\title{
LEARNING AND UNDERSTANDING THE PERFORMANCE OF THE SYSTEM: A STUDY ON DOWNLOAD TIME PERFORMANCE OF UNIVERSITY WEBSITES IN INDIA
}

\author{
G. Sreedhar ${ }^{1}$ \\ ${ }^{1}$ Associate Professor, Department of Computer Science, Rashtriya Sanskrit Vidyapeetha (Deemed University), \\ Tirupati
}

\begin{abstract}
In Today's contest the World Wide Web (WWW) is an important and popular information repository for any type of application. It provides convenient access to almost all kinds of information - from education to entertainment. One can easily understand the behavior of the complex system with a case study. The technique of case study develops skills and knowledge in upcoming students with well illustrated examples. In the present paper a student can easily understand the performance of the website based on the download time of university website. The study demonstrates the various aspects of the website that influences the website. A student can better understand the performance of the system (website) by practical examples rather than theoretical concepts.
\end{abstract}

Keywords—Website Analysis, Download Time Performance, Web Page Analyzer, GTMetrix Tool

\section{INTRODUCTION}

In present situation, any organization must be dynamic in nature to cater the needs of end users. The performance of the organization is basically depending on the behavior of the system in complex situations. The performance management is the sequence of steps to develop standards of the organization in order to achieve the desired goals. According to [12] the main aim of performance system is to test the knowledge of the person in organization in performing his job. As per [13] performance evaluation is the main duty of Human Resource Development manager. According to [14] functionalities of the performance system is considered as a set of activities in a frame work to improve the employees' skills and their roles in the system.

\section{RELATED WORK}

In present education system, students are approaching towards practical approach in understanding the system. Hence the method of studying the system with case studies is becoming popular and effective techniques in understanding the complex system. In this paper the performance of the system is well illustrated with a case study on download time performance of the university websites in India. The download time of website depends on different components of web application like multi media objects, HTML document size, scripts, embedded objects etc.,

\section{METHODOLOGY}

A Website is collection of static and dynamic web pages. The static web pages are static in nature and they convey information to the online user. The dynamic web pages are dynamic in nature and they provide interaction to web application and online users. Thus web application is the collection of static and dynamic web pages. Each web page is consists of continuous text, pictures, graphics, audio and video objects, Active X Control and other embedded objects. Thus World Wide Web is a collection of completely uncontrolled objects. In order to design quality website the web designer has to follow basic guidelines as specified by W3C [9]. In present Internet era [5], designing a quality website is a challenging job even there are many recommendation, guidelines and rules of quality web designing. The authors [1] suggested that good web design is achieved by eliminating flaws from bad web design. The authors [1], [2], [3] and [4] said that always quality Web designing is considered continuous process. The procedure for analysing download time of website initially starts with a web program. The program consists of two parts: extracting components of website with download time and download time performance grades. In the web program, all the components of website with corresponding downloading time are extracted using a web tool namely Web Page Analyzer [10] (fig. 1). The Download time performance grade is obtained using the web tool GTMetrix (fig. 2). The GTMetrix [11] web tool analyses the website download time and evaluates the download time performance in A, B, C, D, $\mathrm{E}$ and $\mathrm{F}$ grades as described in table 1. 


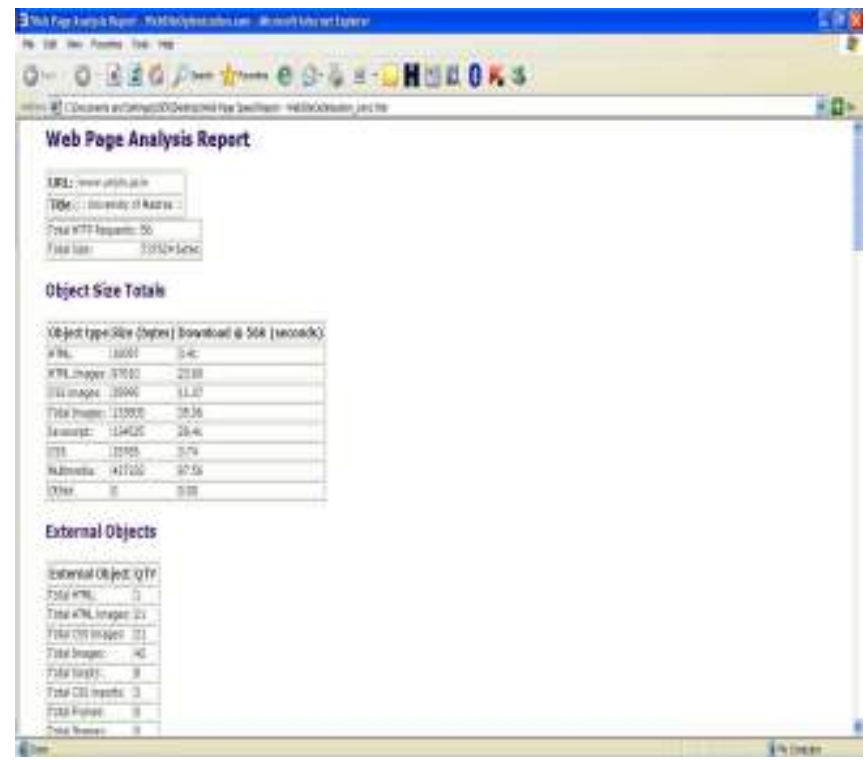

Fig 1 Website Analysis

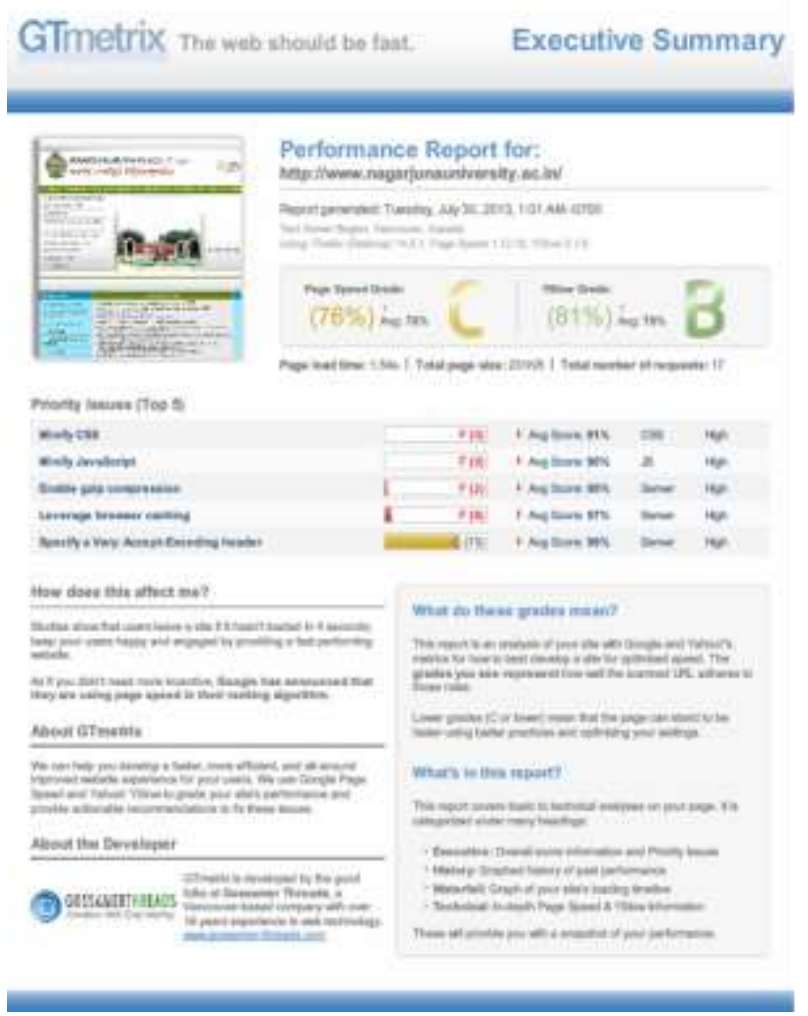

Fig 2 Download time Performance of University Website

Table 1: Description of Download time Performance Grades

\begin{tabular}{|l|l|}
\hline $\begin{array}{l}\text { Download Time } \\
\text { Performance } \\
\text { Grade }\end{array}$ & Description \\
\hline A & Very Good \\
\hline B & Good \\
\hline C & Better than Average \\
\hline D & Average \\
\hline E & Poor \\
\hline F & Very Poor \\
\hline
\end{tabular}

The website size is measured with various objects like images, text, CSS elements, Scripts, pictures, graphics, audio and video and other embedded objects. The download time $(\mathrm{T})$ is related with the size of a page $(\tau)$ and the speed in the established connection line (c) and this relation is shown in equation (1).

$$
T_{\text {Download }} \quad=f(\tau, c) \quad \ldots \quad \text { (l) }
$$

This download time is directly proportional to the page size and inversely proportional to the speed of a given connection line and it is shown in equation (2). A function may be created in order to classify pages as quick or slow access pages, according to a minimum threshold of time (e.g. 10 seconds) for a given speed of a connection line.

$$
\begin{aligned}
& g\left(T_{\text {Download }}\right)= \\
& \text { SlowAccess } T_{\text {Download }} \geq T_{\max }
\end{aligned}
$$

The website size [6] [8] is dependent on various components of the website. These components include Images Size, Documents size, Media Size, Programs or Scripts Size, CSS Size and other objects. As the components sizes increase then automatically the size of website is also increases. The relation between website size and web components is shown in equation (3).

$$
\begin{gathered}
\text { WEBSIZE }=f(\text { IMAGESIZE, DOCSIZE } \\
\text { MEDIASIZE,CSSSIZE, SCRIPTSIZE, OTHEROBJSIZE })
\end{gathered}
$$

$$
\text { ... (3) }
$$

Where WEBSIZE = Website Size

IMAGESIZE = Images Size

DOCSIZE = Documents Size

MEDIASIZE $=$ Multimedia Size

SCRIPTSIZE = Scripts or Programs Size

CSSSIZE = Cascading Style Sheet Size

OTHEROBJSIZE = Other Objects Size like Active X Control Objects, Applets etc.

A regression analysis is carried out to analyse the relationships among these variables. The analysis is carried out through the estimation of a relationship using equation. The results serve the following two purposes.

- Answer the question of how much web size changes with changes in each of the web component's size and

- Forecast or predict the value of web size based on the values of the web component's size

Thus the 10-point metric [7] for evaluating download time of website is developed based on the download time performance grades and the metric is derived using equation (4). 


$10_{P D T}=\quad \begin{gathered}10 \quad \text { if Grade }=A \\ 8 \quad \text { if Grade }=B \\ 6 \quad \text { if Grade }=C \\ 4 \quad \text { if Grade }=D \\ 2 \quad \text { if Grade }=E \\ 0 \quad \text { otherwise }\end{gathered}$

where PDT: Performance Download Time

\section{EVALUATION}

In analyzing the download time performance of the websites, the websites of 10 university websites are considered in evaluation process. The download time of each university websites is analyzed using web program and the corresponding download time performance grade is derived using GTMetrix web tool. The $10_{P D T}$ metric evaluates the website download time and produces the value to describe the performance of university website. The list of 10 university websites with download time performance grades and $10_{P D T}$ metric values are shown in table 2 .

Table 2: Download time Performance Description

\begin{tabular}{|c|c|c|c|}
\hline $\begin{array}{l}\text { S. } \\
\text { No }\end{array}$ & University & $\begin{array}{l}\text { Download } \\
\text { time } \\
\text { Performance } \\
\text { Grade } \\
\end{array}$ & $\begin{array}{l}10 \\
\text { PDT }\end{array}$ \\
\hline 1 & $\begin{array}{l}\text { English and Foreign } \\
\text { Languages University }\end{array}$ & $\mathrm{F}$ & 0 \\
\hline 2 & $\begin{array}{ll}\text { Moulana } & \text { Azad } \\
\text { National } & \text { Urdu } \\
\text { University } & \end{array}$ & $\mathrm{A}$ & 10 \\
\hline 3 & $\begin{array}{l}\text { University } \\
\text { Hyderabad, } \\
\text { Hyderabad }\end{array}$ & $\mathrm{E}$ & 2 \\
\hline 4 & $\begin{array}{ll}\text { Rajiv } & \text { Gandhi } \\
\text { University } & \end{array}$ & $\mathrm{E}$ & 2 \\
\hline 5 & Assam University & $\mathrm{F}$ & 0 \\
\hline 6 & Tezpur University & $\mathrm{F}$ & 0 \\
\hline 7 & $\begin{array}{l}\text { Central University } \\
\text { Bihar }\end{array}$ & $\mathrm{F}$ & 0 \\
\hline 8 & Nagaland University & $\mathrm{F}$ & 0 \\
\hline 9 & $\begin{array}{l}\text { Central University of } \\
\text { Haryana }\end{array}$ & $\mathrm{B}$ & 8 \\
\hline 10 & $\begin{array}{l}\text { Central University of } \\
\text { Himachal Pradesh }\end{array}$ & B & 8 \\
\hline
\end{tabular}

\section{CONCLUSION}

The goal of the present paper is how to understand the performance of the system. A management student can better understand the performance of the system with a case study and hence download time performance of the university websites in India is considered as a case study. In this paper various factors are considered in case study. These factors such as image size, document size, multimedia size, scripts or programs size, cascading style sheets size and objects like Active X Control objects are considered to evaluate website size and ultimately download time of the website. A grading system is used to evaluate the performance of each university website on 10 point scale. In this paper a remarkable effort is made to investigate and identify all possible parameters for quality web design with a case study of university websites in India.

\section{REFERENCES}

[1] Folders, Vincent And Michel Will, "Web Pages that suck: Learn Good Design by looking at Bad Design", SanFrancisco, CA, SYBEX, 1998.

[2] Yogesh Deshpande, San Murugesan Arthla Ginige, Steve Hanse, Daniel Schwabe, Martin Gaedke, Bebo White, "Web Engineering", Journal of Web Engineering, Vol.1. No.1 (2002) 003-017.

[3] Benjamin Yen, Paul Jen-Hwa Hu, May Wang, "Toward and analytical approach for effective Website design: A frame work for modelling, evaluation and enhancement", Electronic Commerce Research and Applications 6 (2007), 159-170.

[4] Benbunan-Fich, R, "Using Protocol Analysis to evaluate the usability of a Commercial Website, Information and Management, 39, 151-163, 2001.

[5] Ali Azad, "Elements of Effective Web Page Design", Global Competitiveness, January, 2001.

[6] Zheng Chen, Shengping Liu, Liu Wenyin, Geguang $\mathrm{Pu}$, Wei-Ying Ma, "Building a Web Thesaurus form Web Link Structure", SIGIR 2003, July 28 - August 1, 2003, Toronto, Canada.

[7] L. Page, S. Brin, R. Motwani and T. Winograd, "The PageRank Citation Ranking: Bring Order to the Web", Technical Report, Stanford University, 1998.

[8] E. Glover, K. Tsioutisiouliklis, S. Lawrence, D.Pennock, G. Flake, "Using Web Structure for Classifying and Describing Web Pages", in Proceedings of WWW2002, Hawaii, May 2002.

[9] Techniques for Web Content Accessibility Guidelines by W3C, http://w3.org

[10] Web Page Analyzer - 0.98 - Website Optimization (Web Page Speed Analysis)

[11] www.GTMetrix.com

[12] Chattopadhayay, R., \& Ghosh.A.K. (2012).Performance appraisal based on a forced distribution system: its drawbacks and remedies. International Journal of Productivity and Performance Management

[13] Judges, T.A., \&Ferris, G.R. (1993).Social Context of Performance Evaluation decisions. Academy of Management Journal.

[14] Armstrong, M. \&. (2005). Managing Performance: Performance management in action London: CIPD 